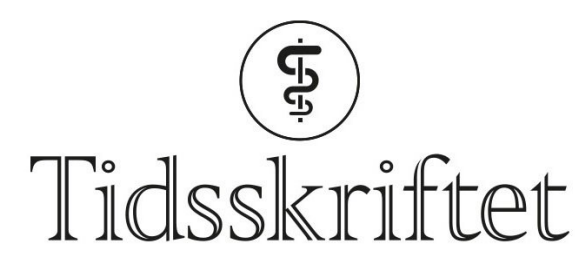

DEN NORSKE LEGEFORENING

\title{
Spontan pneumomediastinum
}

MEDISINEN I BILDER

\section{KAJA JOHANNSON ØDEGAARD}

E-post: Kajajohannson.Odegaard@diakonsyk.no

Kaja Johannson Ødegaard (f. 1981) er lege i spesialisering ved Radiologisk avdeling, Diakonhjemmet Sykehus.

Forfatter har fylt ut ICMJE-skjemaet og oppgir ingen interessekonflikter.

\section{ERIK HAAVARDSHOLM}

Erik Haavardsholm (f. 1982) er overlege ved Radiologisk avdeling, Diakonhjemmet Sykehus. Forfatter har fylt ut ICMJE-skjemaet og oppgir ingen interessekonflikter.

\section{ANDERS HUSBY}

Anders Husby (f. 1964) er overlege ved Kirurgisk avdeling, Diakonhjemmet Sykehus. Forfatter har fylt ut ICMJE-skjemaet og oppgir ingen interessekonflikter.

Spontan pneumomediastinum er en sjelden, men benign og selvbegrensende tilstand som oftest presenterer seg som brystsmerter og eventuelt ledsagende dyspné hos unge menn. Diagnosen kan oftest stilles med røntgen thorax, og ytterligere utredning er vanligvis ikke indisert. 


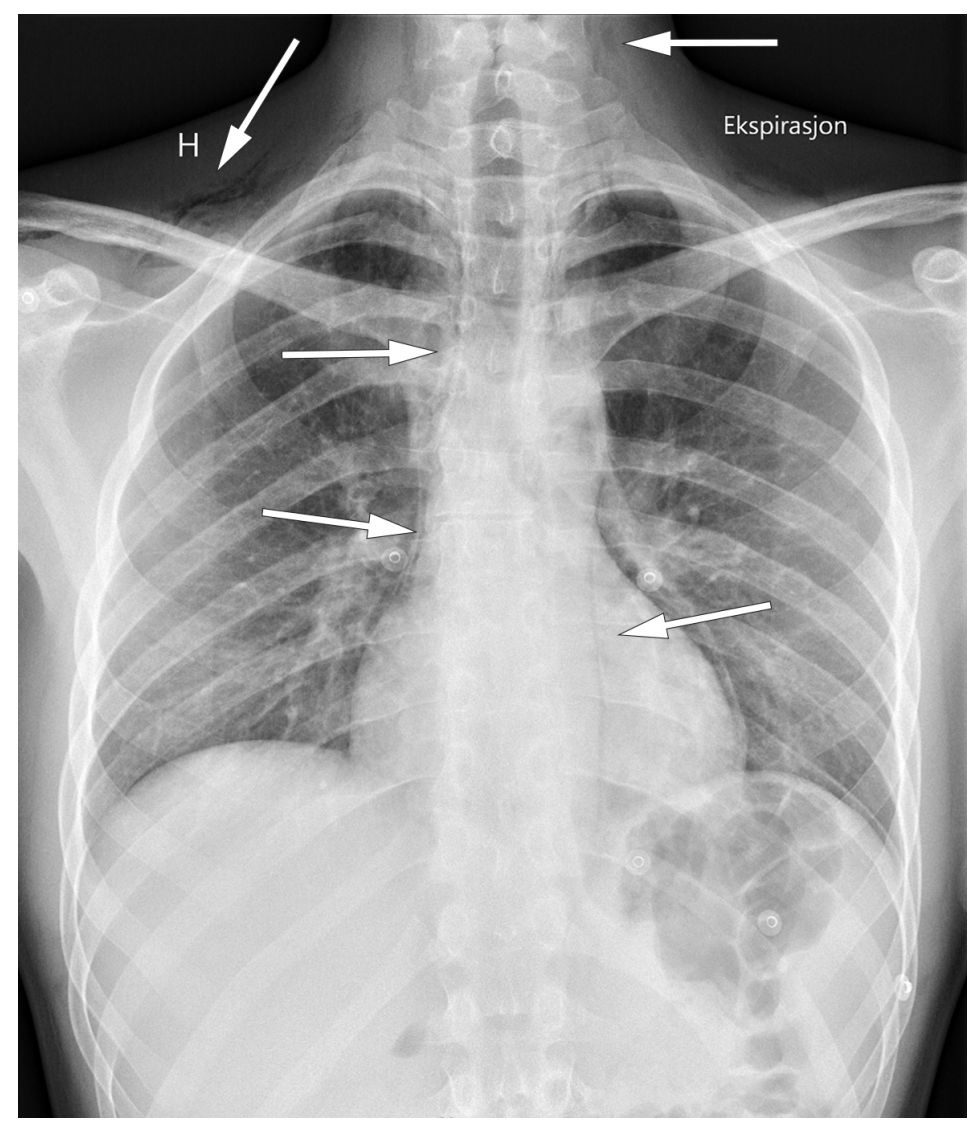

Spontan pneumomediastinum skyldes trolig alveolær ruptur, hvor luften dissekerer seg langs de bronkovaskulære strukturene inn i mediastinum. Utløsende faktor kan være økt intratorakalt trykk som hosteanfall og brekninger, men pneumomediastinum kan også oppstå uten utløsende faktorer. Lungesykdom og røyking kan disponere for tilstanden (1).

Funn ved undersøkelse kan være gnidningslyd som er synkron med hjerteslagene (Hammans tegn), og subkutant emfysem (2). Ytterligere utredning er ikke indisert med mindre sekundære årsaker til pneumomediastinum, som oesophagusruptur, gassproduserende bakterier eller traume, mistenkes (1-4).

Røntgenbildet er tatt av en mann i 2o-årene som fikk akutte brystsmerter med ledsagende dyspné mens han befant seg i ro. Smertene strålte ut til begge skuldre og rygg og ble forverret ved inspirasjon. Han hadde stabile vitale parametere og normale blodprøver.

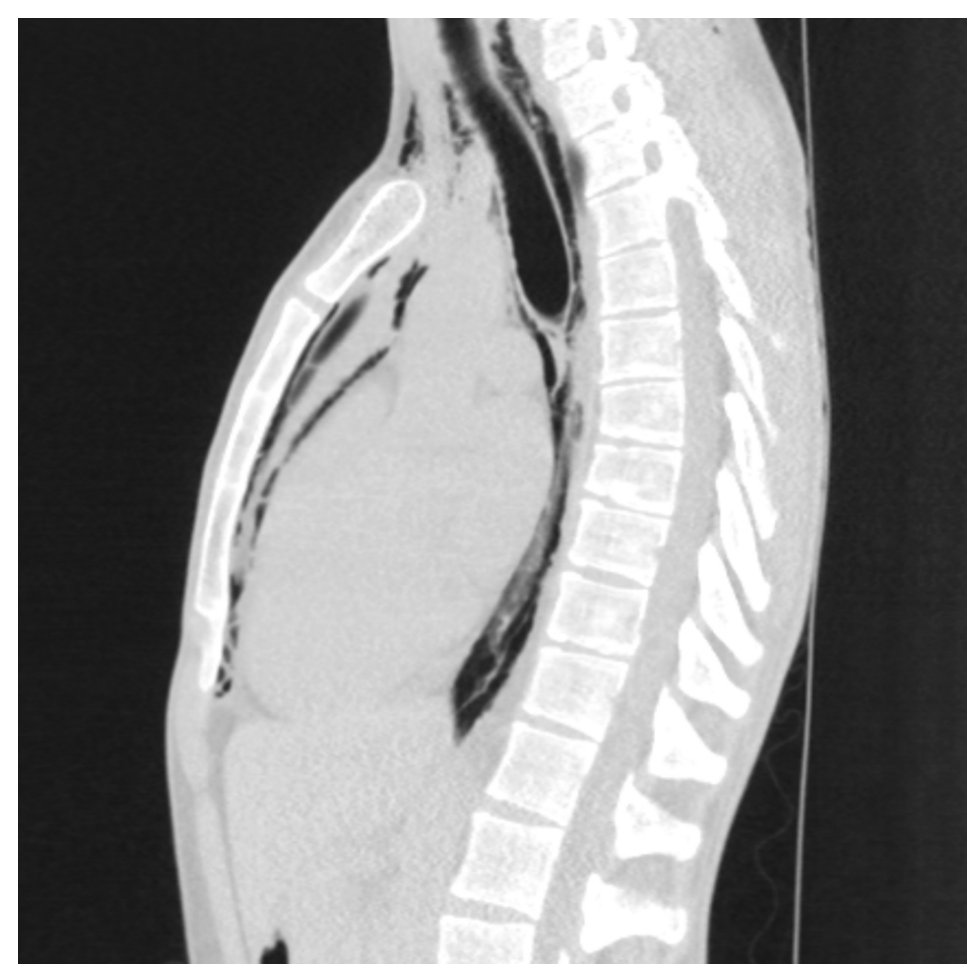


Røntgen thorax viste luft i bløtvevet på halsen og supraklavikulært bilateralt, langs trachea, hjertet og langs aortakonturen lateralt. CT thorax uten intravenøs kontrast bekreftet pneumomediastinum og utelukket pneumothorax. Ved kontroll etter tre uker var pasienten smertefri, og røntgen thorax viste fullstendig regress av pneumomediastinum.

\section{LITTERATUR:}

1. Song IH, Lee SY, Lee SJ et al. Diagnosis and treatment of spontaneous pneumomediastinum: experience at a single institution for 10 years. Gen Thorac Cardiovasc Surg 2017; 65: 280 - 4. [PubMed][CrossRef]

2. Sahni S, Verma S, Grullon J et al. Spontaneous pneumomediastinum: time for consensus. N Am J Med Sci 2013; 5: 460 - 4. [PubMed][CrossRef]

3. Dajer-Fadel WL, Argüero-Sánchez R, Ibarra-Pérez C et al. Systematic review of spontaneous pneumomediastinum: a survey of 22 years' data. Asian Cardiovasc Thorac Ann 2014; 22: 997 - 1002. [PubMed][CrossRef]

4. Okada M, Adachi H, Shibuya Y et al. Diagnosis and treatment of patients with spontaneous pneumomediastinum. Respir Investig 2014; 52:36 - 40. [PubMed][CrossRef]

Publisert: 26. juni 2018. Tidsskr Nor Legeforen. DOI: 10.4045/tidsskr.18.0132 Mottatt 7.2.2018, første revisjon innsendt 11.4.2018, godkjent 24.4.2018.

(C) Tidsskrift for Den norske legeforening 2020. Lastet ned fra tidsskriftet.no 